\title{
Red Blood Cell Distribution Width (RDW) in Chronic Heart Failure: Does it have a Prognostic Value in Every Population?
}

\author{
${ }^{1}$ Department of Pharmacology, College of Clinical Pharmacy, Imam Abdulrahman Bin Faisal University, Dammam, SAUDI ARABIA \\ ${ }^{2}$ Department of Internal Medicine, College of Medicine, Imam Abdulrahman Bin Faisal University, Dammam, SAUDI ARABIA \\ ${ }^{3}$ College of Medicine, Imam Abdulrahman Bin Faisal University, Dammam, SAUDI ARABIA \\ ${ }^{4}$ College of Business, Alfaisal University, Riyadh, SAUDI ARABIA \\ ^Corresponding Author: malem@iau.edu.sa
}

Manal M. Alem ${ }^{1 \star}$, Abdullah M. Alshehri ${ }^{2}$, Muruj A. Alshehri ${ }^{1}$, Mohammed H. AlElaiw ${ }^{3}$, Ali A. Almaa ${ }^{3}$, Rami T. Bustami ${ }^{4}$

Citation: Alem MM, Alshehri AM, Alshehri MA, AlElaiw MH, Almaa AA, Bustami RT. Red Blood Cell Distribution Width (RDW) in Chronic Heart Failure: Does it have a Prognostic Value in Every Population?. Electron J Gen Med. 2022;19(1):em338. https://doi.org/10.29333/ejgm/11400

ARTICLE INFO

Received: 28 Apr. 2021

Accepted: 26 Sep. 2021

\begin{abstract}
Objectives: Chronic heart failure (CHF) is a global health issue with notable morbidity and mortality. Currently, red cell distribution width (RDW) has appeared to be potential prognostic marker in patients with CHF.This study aims to assess the prognostic value of RDW in Saudi population with CHF.

Methods: This study was a retrospective cohort study that included $233 \mathrm{CHF}$ patients treated with standard antifailure drugs. RDW were ascertained at baseline with 2-D echocardiographic assessments of left ventricular mass and function. The follow up period was 24 months. Primary endpoint was the relationship between RDW and allcause mortality (ACM). Secondary endpoints included the potential association with major adverse cardiovascular events (classical 3-point MACE).

Results: The mean age of patients was $60.15 \pm 12.24$ years, and $64.8 \%$ were males. Baseline RDW was $14.40(13.50$, $15.80) \%$ (median, and interquartile ranges); 43 deaths occurred during the follow-up period. RDW was found to be the most significant and independent predictor of ACM, with a hazard ratio (HR) of $1.238(95 \% \mathrm{Cl} ; 1.090,1.407)$ $(P=0.001)$. While RDW change over 12 months had similar predictive value for $A C M$ with $\mathrm{HR} 1.226(95 \% \mathrm{Cl} ; 1.117$, 1.346) $(\mathrm{P}<0.0001)$. RDW was also found to be a significant and independent predictor for secondary endpoints.

Conclusion: Our study supports the usefulness of RDW as an independent prognostic indicator for ACM and other CV outcomes in Saudi population with CHF.
\end{abstract}

Keywords: red blood cell distribution width, anemia, heart failure, left ventricular mass index, all-cause mortality

\section{INTRODUCTION}

One of the most prevalent diseases worldwide is chronic heart failure [CHF). It is linked with low quality of life and notable morbidity/mortality [1]. In Saudi Arabia, the Heart function Assessment Registry Trial in Saudi Arabia (HEARTS) reported that CHF occurs in mostly younger age, with much higher rates of diabetes mellitus (DM), and predominant left ventricular (LV) systolic dysfunction [2]. Considering the age factor, the established adverse effects of DM on patients with CHF [3], and the strong predictive value of reduced LV ejection fraction (EF) on cardiovascular outcomes in such patient population [4], indicates the obvious need to identify new risk factors/biological markers that could guide the treatment strategy and/or identify inadequate management.RDW determines the variation in red blood cell (RBC) sizes in peripheral blood smear. A rise in RDW is often, directly or indirectly, results from more than one factor, e.g., advancing age [5], inflammatory cascades [6], oxidative stress [7], anemiasubtypes [8], and reduced kidney function [9]. Fortunately, RDW assessment is now a routine test in the complete blood count. The prognostic value of RDW was first established in $\mathrm{CHF}$ by the CHARM (Candesartan in Heart Failure: Assessment of Reduction in Mortality and Morbidity) program, which involved
2,679 patients, where RDW was the most powerful predictor of all-cause mortality amongst 36 laboratory tests [10]. Such results were supported later by other studies [11-13]. Against this background, the present cohort study was planned to evaluate the RDW prognostic value in Saudi population with CHF.

\section{SUBJECTS}

The target population was $\mathrm{CHF}$ above 18 years of age, who are treated in King Fahd Hospital of the University (KFHU), Al Khobar, Saudi Arabia, with standard anti-failure drugs (irrespective of LV ejection fraction or New York Heart Association NYHA functional class).

\section{Exclusion Criteria}

- Acute heart failure

- Serum $\mathrm{Hb}<9 \mathrm{gr} / \mathrm{dl} /$ hematocrit $<30 \%$

- Known inherited hemoglobinopathy (sickle cell disease, thalassemia) with documented hemoglobin electrophoresis

- Iron deficiency anemia/megaloblastic anemia (with documented serum ferritin, transferrin saturation, or macrocytosis on peripheral blood smear) 
- Severe reduction of kidney function (eGFR $<30$ $\mathrm{mL} / \mathrm{min} / 1.73 \mathrm{~m}^{2}$ )

- $\mathrm{ESR}>20 \mathrm{~mm} / \mathrm{hr} / \mathrm{CRP}>0.3 \mathrm{mg} / \mathrm{dl}$ (suggestive of chronic inflammatory conditions)

- Malignancy/myelodysplastic syndrome

- Recent hemorrhage/transfusion (within 3 months)

\section{METHODS}

This study was an observational, with a retrospective cohort design, to evaluate the relationship between RDW and ACM, during a follow up period of 24 months (from RDW measurements) as the primary endpoint. Secondary endpoints included the association of RDW with classical 3-point major adverse cardiovascular events (classical 3-point MACE), defined as a composite of nonfatal stroke, nonfatal myocardial infarction (MI), and cardiovascular death.

\section{Ethical Approval}

The protocol was approved by the Institutional Review Board (IRB Number IRB-2019-05-009), Deanship of Scientific Research, Imam Abdulrahman Bin Faisal University, Dammam, Saudi Arabia. The study was carried out in accordance with the Declaration of Helsinki (2013). Verbal consents from the patients/next of kin was taken by the investigators, through telephone conversations to check for study endpoints.

\section{Data Collection}

Data collected by the investigators; MAA, MHA, and AAA at study entry included: demographic information, NYHA functional class, and co-morbidities. Using 2-D images of echocardiograms, left ventricular mass index (LVMI), and ejection fraction (EF) were calculated [14]. The primary/secondary endpoints were extracted from the electronic records, and the patients/next of kin were contacted to confirm. Cardiovascular deaths were classified as in the CHARM program [4].

\section{Red Blood Cell Distribution Width (RDW) Assessment}

Complete blood count parameters were examined with an automated hematology analyzer DxH 800 (Beckman Coulter (UK) Ltd, High Wycombe, UK). RDW was calculated as the coefficient of variation (CV) of the red blood cell volume distribution (\%).

$\mathrm{RDW}=[1$ standard deviation of $\mathrm{RBC}$ volumes $/ \mathrm{MCV}] \times 100$

Where MCV is the average volume (size) of the patient's RBC (in femtoliters, $\mathrm{fL}$ ). The normal range of RDW obtained from our laboratory was $11.5-14.5 \%$.

\section{Statistical Analysis}

Data are reported as mean \pm SD, or median and ranges of values for non-normally distributed data. Patients were compared through unmatched Student's t-test, Mann-Whitney $\mathrm{U}$ test, or the chi-square test, based on the kind of data collected. The relationship between RDW values (as a continuous variable) and the primary endpoint (ACM) was assessed using Cox proportional hazards model (within 24 month). The model included variables the number of which was based on events occurred [15]. These variables were; age, sex, RDW, eGFR, LVMI, and EF.RDW association with secondary endpoints (classical 3-point MACE) was assessed using binary logistic regression, with goodness-of-fit tests. All statistical analyses were done by MedCalc statistical software (version 19.1.13, MedCalc software, Ostend, Belgium). Statistical significance was defined with $\mathrm{p}<0.05$.

\section{RESULTS}

\section{Baseline Characteristics}

The initial search for heart failure/cardiac failure patients (Jan 2005- Dec 2016) revealed 876 patients. A total of 233 eligible patients were enrolled, after excluding 643 patients according to the pre-determined exclusion criteria. The participant's clinical characteristics and anti-failure medications are demonstrated in Table 1. Their hematological, biochemical, and echocardiographic characteristics are demonstrated in Table 2.

\section{Study Population as per their Baseline RDW Values}

Dividing the study population based on a cut limit of RDW of $14.5 \%$ showed that patients with higher RDW had worse heart failure severity, higher prevalence of hypertension and bronchial asthma, and their medications showed less number of patients maintained on aspirin and sulphonylureas, and more maintained on loop diuretics and warfarin (Table 1).

\section{Study Endpoints \\ Primary endpoint}

Within 24 months from baseline RDW measurements, 43 deaths occurred (18.5\%), 39 of which (16.7\%) were considered cardiovascular deaths. The average time from baseline RDW values till death was $14.92 \pm 6.61(95 \% \mathrm{Cl} ; 12.89,16.95)$ months. The predictive value of RDW of ACM in the univariate analysis as well as the multivariate analysis is shown (Table 3 ).

\section{The change of RDW over 12 months period and all-cause mortality}

Data related to the change in RDW values from baseline was available for 215 patients over a mean duration of $12.46 \pm 5.21$ (SD) months. The recorded change was $0.20(-0.40,0.90) \%$ (median, and interquartile ranges). Univariate cox proportional hazard model showed that the change in RDW over 12 months has a significant predictive value for all-cause mortality, with HR 1.241 (95\% Cl; 1.159, 1.329) $(\mathrm{P}<0.0001)$. The change in RDW (when replaced baseline RDW values) was the strongest predictor of ACM in the multivariate model, HR $1.226(95 \% \mathrm{Cl}$; $1.117,1.346)(P<0.0001)$ (model not shown). Figure 2 shows the survival analysis of those classified patients (91 patients had a decrease/ no change, and 124 patients had an increase). Classifying the patients as per their baseline RDW and the trend of change reveals; 120 patients had a normal baseline RDW (in 40, it decreased, while in 80, it increased) and; 95 patients had high RDW at baseline (in 51, it decreased, while in 44, it increased). The four group's survival analyses are displayed in Figure 3.

\section{Secondary endpoints}

The same predictors were utilized in order to assess the relationship of RDW with stroke (22 events), MI (39 events), CV death (39 events), and MACE (84 events). Such analysis has showed that RDW has significant and independent association with stroke; HR $1.330(95 \% \mathrm{Cl} ; 1.047,1.689)(\mathrm{P}=0.017)$, CV death; HR 1.236 (95\% Cl; 1.029, 1.484) ( $\mathrm{P}=0.020)$, and MACE; HR 1.162 (95\% Cl; 1.001, 1.349) ( $\mathrm{P}=0.043)$ (models not shown). 
Table 1. Baseline clinical and pharmacologic characteristics of study patients as one group and divided based on RDW values

\begin{tabular}{|c|c|c|c|c|}
\hline Characteristic & $\begin{array}{l}\text { All patients } \\
\mathrm{N}=\mathbf{2 3 3}\end{array}$ & $\begin{array}{l}\text { Patients with RDW } \leq 14.5 \% \\
\qquad \mathrm{~N}=127\end{array}$ & $\begin{array}{l}\text { Patients with RDW }>14.5 \% \\
\qquad \mathrm{~N}=106\end{array}$ & P value \\
\hline Age (years) & $60.15 \pm 12.2$ & $59.37 \pm 12.35$ & $61.08 \pm 12.11$ & 0.29 \\
\hline Male sex & $151(64.8 \%)$ & $90(70.9 \%)$ & $61(57.6 \%)$ & 0.034 \\
\hline $\mathrm{BMI}\left(\mathrm{kg} / \mathrm{m}^{2}\right)^{\star}$ & $29.05(25.10,33.30)$ & $28.9(25.40,33.20)$ & $29.4(24.80,33.70)$ & 0.61 \\
\hline NYHA class ** & & & & $<0.001$ \\
\hline 1 & $29(12.4 \%)$ & $25(19.7 \%)$ & $4(3.8 \%)$ & \\
\hline 2 & $89(38.2 \%)$ & $49(38.6 \%)$ & $40(37.7 \%)$ & \\
\hline 3 & $75(32.2 \%)$ & $40(31.5 \%)$ & $35(33.0 \%)$ & \\
\hline 4 & $35(15.0 \%)$ & $11(8.7 \%)$ & $24(22.6 \%)$ & \\
\hline Ischemic etiology of CHF & $156(67.0 \%)$ & $92(72.4 \%)$ & $64(60.4 \%)$ & 0.051 \\
\hline \multicolumn{5}{|l|}{ Co-morbidities } \\
\hline Hypertension & $180(77.3 \%)$ & $90(70.9 \%)$ & $90(84.9 \%)$ & 0.011 \\
\hline Diabetes mellitus (type 2) & $166(71.2 \%)$ & $92(72.4 \%)$ & $74(69.8 \%)$ & 0.66 \\
\hline Dyslipidaemia & $131(56.2 \%)$ & $65(51.2 \%)$ & $66(62.3 \%)$ & 0.089 \\
\hline Arrhythmias ${ }^{\star \star \star} / \mathrm{AF}$ & $51(21.9 \%) / 45(19.3 \%)$ & $24(18.9 \%) / 20(15.7 \%)$ & $27(25.5 \%) / 25(23.6 \%)$ & $0.23 / 0.13$ \\
\hline Bronchial asthma & $21(9.0 \%)$ & $7(5.5 \%)$ & $14(13.2 \%)$ & 0.041 \\
\hline \multicolumn{5}{|l|}{ Cardiac medication } \\
\hline ACEIs/ARBs & $133(57.1 \%) / 69(29.6 \%)$ & $74(58.3 \%) / 35(27.6 \%)$ & $59(55.7 \%) / 34(32.1 \%)$ & $0.69 / 0.45$ \\
\hline Beta blockers & $192(82.4 \%)$ & $110(86.6 \%)$ & $82(77.4 \%)$ & 0.065 \\
\hline CCBs & $53(22.8 \%)$ & $30(23.6 \%)$ & $23(21.7 \%)$ & 0.73 \\
\hline Aspirin/Clopidogrel & $194(83.3 \%) / 90(38.6 \%)$ & $114(89.8 \%) / 47(37.0 \%)$ & $80(75.5 \%) / 43(40.6 \%)$ & $0.004 / 0.58$ \\
\hline Warfarin & $35(15.0 \%)$ & $13(10.2 \%)$ & $22(20.8 \%)$ & 0.025 \\
\hline Thiazide diuretics & $39(16.7 \%)$ & $25(19.7 \%)$ & $14(13.2 \%)$ & 0.19 \\
\hline Loop diuretics & $157(67.4 \%)$ & $74(58.3 \%)$ & $83(78.3 \%)$ & 0.001 \\
\hline Spironolactone & $89(38.2 \%)$ & $43(33.9 \%)$ & $46(43.4 \%)$ & 0.14 \\
\hline \multicolumn{5}{|l|}{ Antidiabetic medication } \\
\hline Insulin & $70(30.0 \%)$ & $36(28.3 \%)$ & $34(32.1 \%)$ & 0.54 \\
\hline Sulphonylureas & $53(22.8 \%)$ & $41(32.3 \%)$ & $12(11.3 \%)$ & $<0.001$ \\
\hline Metformin & $99(42.5 \%)$ & $59(46.5 \%)$ & $40(37.7 \%)$ & 0.18 \\
\hline
\end{tabular}

Values are expressed as mean \pm SD or number (percentage of patients). Median with interquartile ranges are used for non-normally distributed data.

Abbreviations: BMI, body mass index; NYHA, New York Heart Association; AF, atrial fibrillation (paroxysmal and permanent); ACEls, angiotensin-converting enzyme inhibitors; ARBs, angiotensin receptor blockers; CCBs, calcium channel blockers.

Missing data from medical records: ${ }^{\star} 13$ patients did not have their heights recorded, ${ }^{\star \star} 5$ patients did not have their NYHA class recorded, ${ }^{\star \star \star}$ Other 6 arrhythmias (premature ventricular contractions, atrial flutter, 2 supraventricular tachycardia, and 2 ventricular tachycardia)

Table 2. Hematological, biochemical, and echocardiographic characteristics of patients, overall and by RDW group

\begin{tabular}{|c|c|c|c|c|}
\hline Characteristic & $\begin{array}{l}\text { All patients } \\
\mathrm{N}=\mathbf{2 3 3}\end{array}$ & $\begin{array}{l}\text { Patients with RDW } \leq 14.5 \% \\
\mathrm{~N}=127\end{array}$ & $\begin{array}{l}\text { Patients with RDW }>14.5 \% \\
\qquad N=106\end{array}$ & $P$ value \\
\hline \multicolumn{5}{|l|}{ Hematological } \\
\hline $\mathrm{Hb}(\mathrm{g} / \mathrm{dl})$ & $13.15 \pm 1.84$ & $13.77 \pm 1.64$ & $12.41 \pm 1.81$ & $<0.001$ \\
\hline Hematocrit (\%) & $39.46 \pm 5.34$ & $40.83 \pm 4.94$ & $37.81 \pm 5.36$ & $<0.001$ \\
\hline RDW (\%) & $14.40(13.50,15.80)$ & $13.50(13.00,14.00)$ & $15.95(15.30,17.30)$ & $<0.001$ \\
\hline \multicolumn{5}{|l|}{ Biochemical } \\
\hline Serum creatinine (mg/dL) & $1.00(0.90,1.30)$ & $1.00(0.80,1.20)$ & $1.10(0.90,1.30)$ & 0.019 \\
\hline eGFR $\left(\mathrm{ml} / \mathrm{min} / 1.73 \mathrm{~m}^{2}\right)$ & $72.00(57.00,89.00)$ & $76.00(62.00,93.00)$ & $66.00(54.00,81.00)$ & $<0.001$ \\
\hline \multicolumn{5}{|l|}{ Echocardiographic } \\
\hline Left ventricular mass index $\left(\mathrm{g} / \mathrm{m}^{2}\right)^{\star}$ & $107.00(82.00,131.00)$ & $108.00(85.00,136.00)$ & $104.50(78.00,127.75)$ & 0.28 \\
\hline Ejection fraction $(E F)^{\star \star}$ & $41.00(30.00,55.00)$ & $43.00(33.00,55.00)$ & $40.00(28.00,55.00)$ & 0.20 \\
\hline
\end{tabular}

Values are expressed as mean \pm SD or number (percentage of patients). Median with interquartile ranges are used for non-normally distributed data. Abbreviations: $\mathrm{Hb}$, hemoglobin; eGFR, estimated glomerular filtration rate

Missing data from medical records; *data from 211 patients (10 patients had no matching echocardiograms, 3 had echocardiograms for EF estimation only, and 9 had no height recorder to calculate LVMI), ${ }^{\star \star}$ data from 223 patients 
Table 3. Univariate and multivariate Cox proportional hazard models of RDW and ACM

\begin{tabular}{|c|c|c|}
\hline \multicolumn{3}{|c|}{ Univariate analysis } \\
\hline Variable & HR $(95 \% \mathrm{Cl})$ & $P$-value \\
\hline Age & $1.083(1.050,1.118)$ & $<0.001$ \\
\hline RDW & $1.213(1.075,1.368)$ & 0.002 \\
\hline eGFR & $0.982(0.968,0.997)$ & 0.017 \\
\hline LVMI & $1.006(1.000,1.013)$ & 0.049 \\
\hline $\mathrm{EF}$ & $0.994(0.971,1.017)$ & 0.607 \\
\hline Sex (female) & $1.489(0.816,2.727)$ & 0.195 \\
\hline \multicolumn{3}{|c|}{ Multivariate analysis } \\
\hline Variable & HR $(95 \% \mathrm{Cl})$ & $P$-value \\
\hline Age & $1.078(1.043,1.114)$ & $<0.001$ \\
\hline RDW & $1.238(1.090,1.407)$ & 0.001 \\
\hline eGFR & $0.990(0.975,1.005)$ & 0.184 \\
\hline LVMI & $1.010(1.002,1.018)$ & 0.016 \\
\hline $\mathrm{EF}$ & $1.010(0.984,1.036)$ & 0.46 \\
\hline Sex (female) & $1.002(0.512,1.962)$ & 0.99 \\
\hline
\end{tabular}

Abbreviations: RDW, red blood cell distribution width; eGFR, estimated glomerular filtration rate; LVMI, left ventricular mass index; EF, ejection fraction Overall Model Fit Null model -2 Log Likelihood 460.214; Full model -2 Log Likelihood 402.475; Chi-squared 57.739; Significance level P < 0.0001

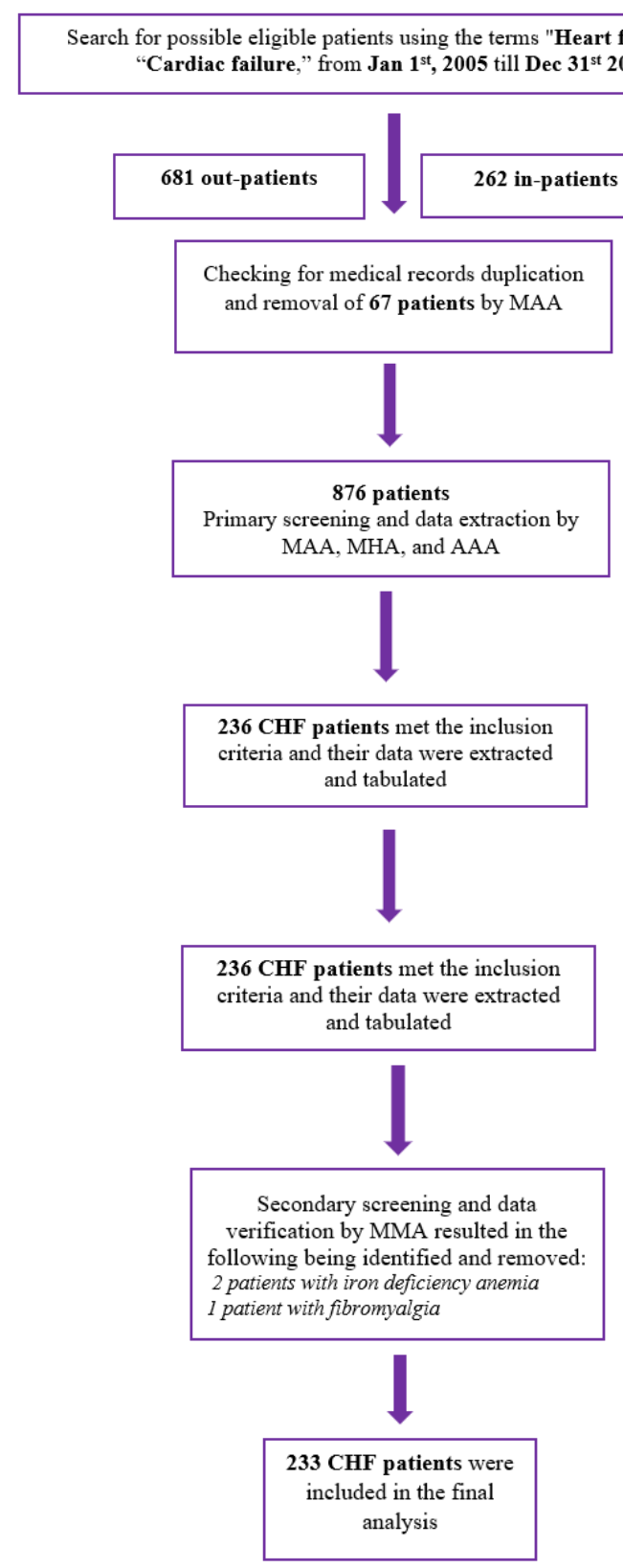

Figure 1. Study flow chart 

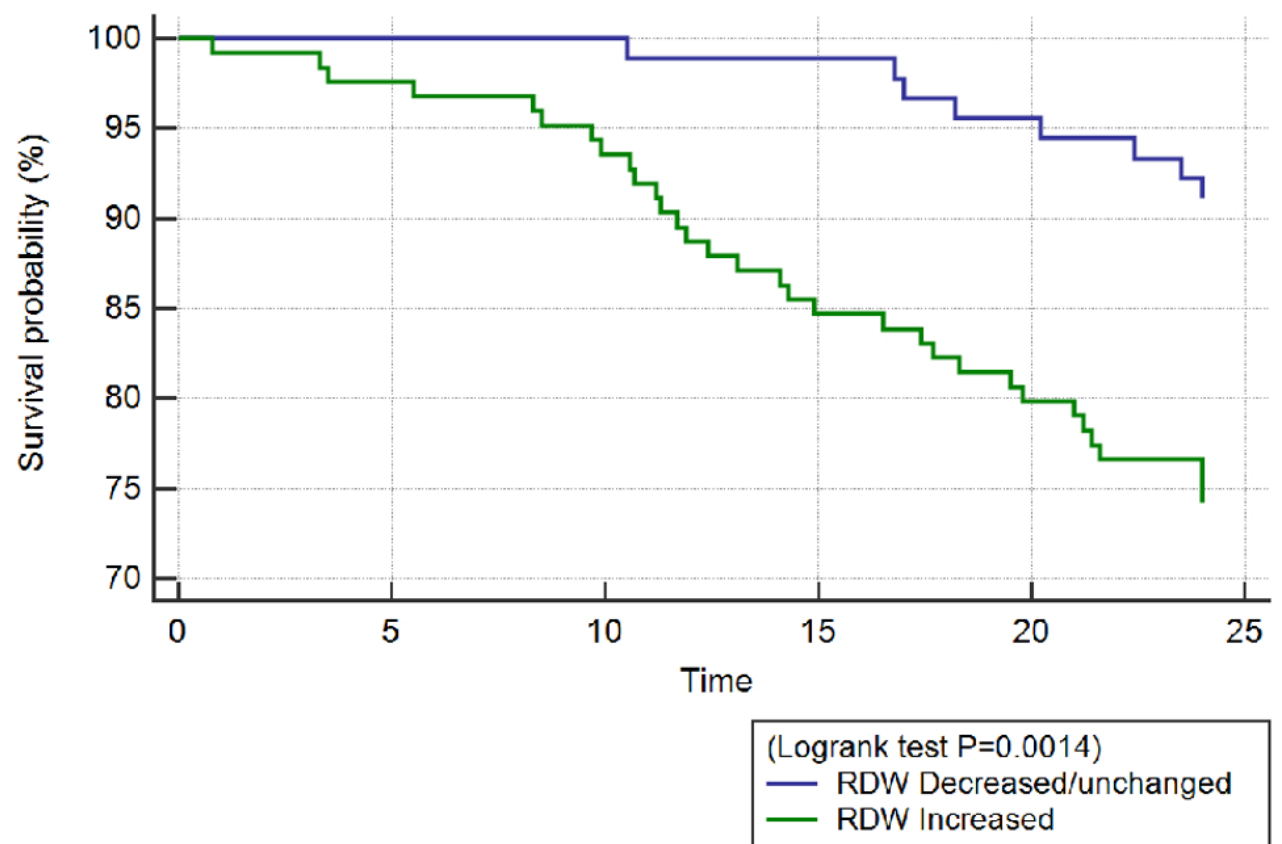

Figure 2. Kaplan-Meier survival analysis in CHF patients based on RDW change over 12 months

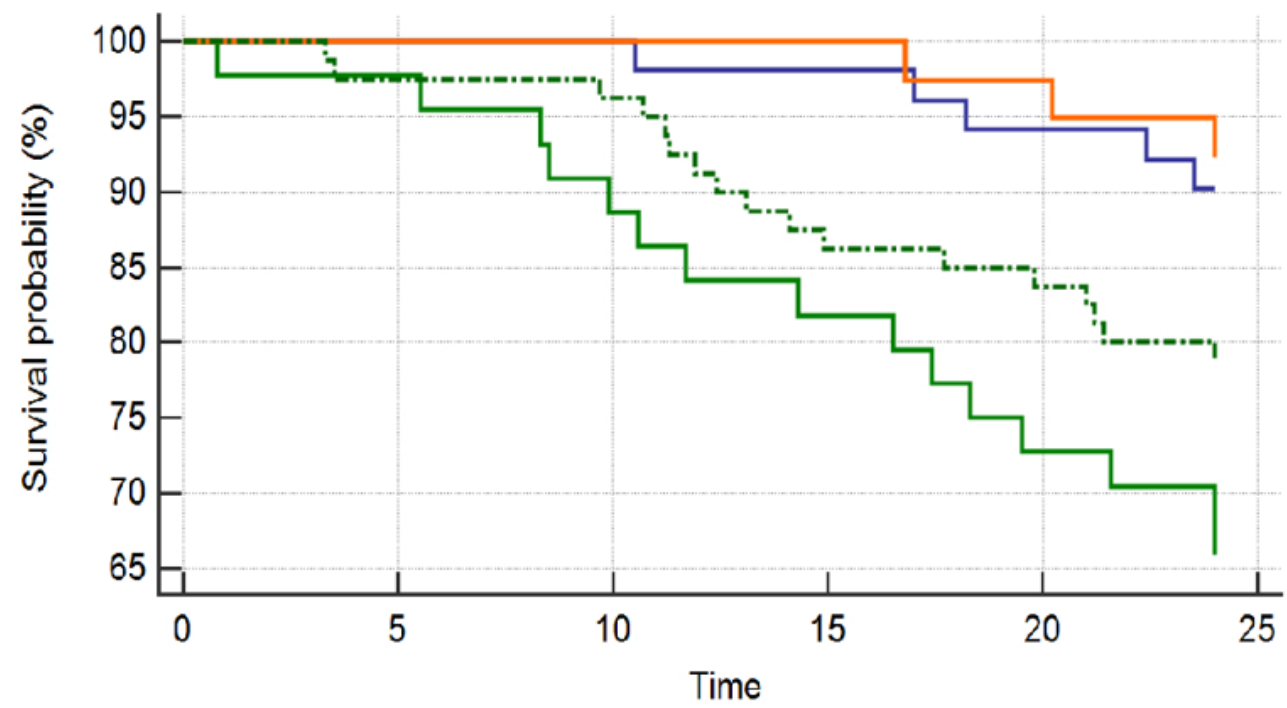

(Logrank test $\mathrm{P}=0.0030$ )

- RDW > 14.5\%- Decreased/unchanged

- RDW $>14.5 \%$ - Increased

- RDW $\leq 14.5 \%$ - Decreased/unchanged

-.-. RDW $\leq 14.5 \%$ - Increased

Figure 3. Kaplan-Meier survival analysis in CHF patients based on baseline RDW value and its change over 12 months

\section{DISCUSSION}

This study is the first to show that one-occasional assessment of RDW has a predictive value to ACM, stroke, CV death, and MACE in Saudi population with CHF. In addition, it appears that the trend of change (if it continues to rise) of such parameter with time is of equal importance. The magnitude of predictability found for ACM in our study is greater than other studies/meta-analyses in the literature $[4,10,12,13]$. In particular interest, the usefulness of RDW in predicting clinical outcomes in this study is superior to echocardiographic parameters, and such finding was reported in the literature $[16,17]$.
To consolidate these findings and base future recommendations, additional studies are required to confirm the reliability and robustness of RDW for routine clinical practice. Four important considerations warrant early attention and investigation. First, a large population-based study identified that $29 \%$ of the variability in RDW is due to a genetic component that increases with age: this issue needs clarification [18]. In the future, exploration of ethnic/ genetic factors to establish reference ranges and the predictive value of RDW in different populations will almost certainly require large, comparative epidemiological studies. Secondly, there is technological heterogeneity amongst different hematological analysers [19]; to solve this issue, standardization of the methods of analysis is essential, in accordance with the 
recommendations of the International Council for Standardization in Haematology (ICSH) [20]. Thirdly, it is still not clear which factors/clinical conditions contribute significantly to RDW and, in turn, to what extent these are genetically determined. These factors should be possibly explored in different patient's population by relating the summative results to the clinical co-morbidities, but this piece of information is beyond the scope of this study.

Finally, for a future perspective on whether different drug treatments might have influenced RDW measurements, our study does not have enough statistical support to draw definitive conclusions but it has shown that patients with high RDW values used less of aspirin and sulphonylureas as and more of warfarin and loop diuretics, but this trend could not be separated from the primary indications of these drugs -the ischemic etiology of CHF, type $2 \mathrm{DM}, \mathrm{AF}$, and NYHA functional class III-IV respectively. Nevertheless, it remains possible that these drug classes might influence "at least partially" the general inflammatory state and the measured RDW values. The anti-inflammatory action of anti-platelet/low-dose aspirin has been reported in human subjects [21] and the antiinflammatory activity of sulphonylureas as has been shown in diabetic patients [22]. Data on the effects of warfarin on parameters of inflammatory reactions are sparse in the literature, with both stimulatory and inhibitory [23]. The same contradictory findings apply to furosemide therapy as well [24,25].

In summary, RDW is an emerging essential biomarker which has an independent prognostic value in patients with $\mathrm{CHF}$ for ACM, stroke, and CV death during the specified followup period. Before definitive recommendations can be made with respect to clinical intervention, however, a number of clarifications are required: for example, the establishment of reference values in different populations, taking into consideration genetic differences, age, sex, and different comorbidities. Further, the effects of different pharmacological agents need to be explored and incorporated into future predictive models.

\section{Study Limitations}

There are two major limitations in this study. First; we did not include patients who presented before 2005, for lack of completeness of echocardiogram reports and we excluded those patients whose RDW might have been raised by hematological disorders. Second; our study did not include the comparison of RDW against that of brain natriuretic peptide (BNP), because it is not a routine test for heart failure patients in our hospital.

\section{CONCLUSION}

This study has shown that RDW is an easy, widely available, routine blood test with significant predictive value for ACM and CV events in patients with CHF. These findings are consistent with other populations. However, reference values, standardized techniques, are a priority, and so are identifying established factors that could contribute to high RDW readings. For now, a closer look at RDW in CBC reports is worth considering.

Author contributions: MMA: Conceived and designed the study, contributed data or analysis tools, verified the date, performed the analysis, and wrote the paper. AMA: Conceived and designed the study, collected the data, contributed data or analysis tools, and revised the paper. MAA: Conceived and designed the search process, collected the data, contributed data or analysis tools. MHA: Conceived and designed the search process, collected the data, contributed data or analysis tools. AAA: Conceived and designed the search process, collected the data, contributed data or analysis tools. RTB: Conceived and designed the study, performed the analysis, and revised the paper. All authors have sufficiently contributed to the study, and agreed with the results and conclusions.

Funding: No funding source is reported for this study.

Acknowledgements: We thank Mr Abdul Majeed Alam of the Department of Medical Records, KFHU for his help with in-patient search, Dr.Ashok Upadhyaya for his help with out-patient search, and Dr Alaa Alshehri for her help with data collection.

Declaration of interest: No conflict of interest is declared by authors.

Availability of supporting data: The data which support the findings of this study are available from the corresponding author upon request.

\section{REFERENCES}

1. Savarese G, Lund LH. Global public health burden of heart failure. Card Fail Rev 2017 Apr;3(1):7-11. https://doi.org/10.15420/cfr.2016:25:2

2. Alhabeeb W, Elasfar A, AlBackr H, AlShaer F, Almasood A, AlFaleh $\mathrm{H}$, et al. Clinical characteristics, management and outcomes of patients with chronic heart failure: Results from the heart function assessment registry trial in Saudi Arabia (HEARTS-chronic). Int J Cardiol 2017 May 15;235:949. https://doi.org/10.1016/j.ijcard.2017.02.087 PMid: 28284505

3. Dauriz M, Mantovani A, Bonapace S, Verlato G, Zoppini G, Bonora $E$, et al. Prognostic Impact of Diabetes on Longterm Survival Outcomes in Patients With Heart Failure: A Meta-analysis. Diabetes Care 2017 Nov;40(11):1597-605. https://doi.org/10.2337/dc17-0697 PMid:29061587

4. Solomon SD, Anavekar N, Skali H, McMurray JJ, Swedberg $\mathrm{K}$, Yusuf $\mathrm{S}$, et al. Influence of ejection fraction on cardiovascular outcomes in a broad spectrum of heart failure patients. Circulation 2005 Dec 13;112(24):3738-44. https://doi.org/10.1161/CIRCULATIONAHA.105.561423 PMid:16330684

5. Cheng CK, Chan J, Cembrowski GS, van Assendelft OW. Complete blood count reference interval diagrams derived from NHANES III: stratification by age, sex, and race. Lab Hematol 2004;10(1):42-53. https://doi.org/10.1532/LH96. 04010 PMid: 15070217

6. Lippi G, Targher G, Montagnana M, Salvagno GL, Zoppini G, Guidi GC. Relation between red blood cell distribution width and inflammatory biomarkers in a large cohort of unselected outpatients. Arch Pathol Lab Med 2009 Apr;133(4):628-32. https://doi.org/10.5858/133.4.628 PMid: 19391664

7. Friedman JS, Lopez MF, Fleming MD, Rivera A, Martin FM, Welsh ML, et al. SOD2-deficiency anemia: protein oxidation and altered protein expression reveal targets of damage, stress response, and antioxidant responsiveness. Blood 2004 Oct 15;104(8):2565-73. https://doi.org/10.1182/blood2003-11-3858 PMid:15205258

8. Roberts GT, El Badawi SB. Red blood cell distribution width index in some hematologic diseases. Am J Clin Pathol 1985 Feb;83(2):222-6. https://doi.org/10.1093/ajcp/83.2.222 PMid:3969961 
9. Lippi G, Targher G, Montagnana M, Salvagno GL, Zoppini G, Guidi GC. Relationship between red blood cell distribution width and kidney function tests in a large cohort of unselected outpatients. Scand J Clin Lab Invest 2008;68(8):745-8. https://doi.org/10.1080/00365510802213 550 PMid: 18618369

10. Felker GM, Allen LA, Pocock SJ, Shaw LK, McMurray JJ, Pfeffer MA, et al. Red cell distribution width as a novel prognostic marker in heart failure: data from the CHARM Program and the Duke Databank. J Am Coll Cardiol $2007 \mathrm{Jul}$ 3;50(1):40-7. https://doi.org/10.1016/j.jacc.2007.02.067 PMid: 17601544

11. Al-Najjar Y, Goode KM, Zhang J, Cleland JG, Clark AL. Red cell distribution width: an inexpensive and powerful prognostic marker in heart failure. Eur J Heart Fail 2009 Dec;11(12):1155-62. https://doi.org/10.1093/eurjhf/hfp147 PMid:19926599

12. Cauthen CA, Tong W, Jain A, Tang WH. Progressive rise in red cell distribution width is associated with disease progression in ambulatory patients with chronic heart failure. J Card Fail 2012 Feb;18(2):146-52. https://doi.org/10.1016/j.cardfail.2011.10.013 PMid:22300783 PMCid:PMC3272251

13. Huang YL, Hu ZD, Liu SJ, Sun Y, Qin Q, Qin BD, et al. Prognostic value of red blood cell distribution width for patients with heart failure: a systematic review and metaanalysis of cohort studies. PLoS One 2014;9(8):e104861. https://doi.org/10.1371/journal.pone.0104861 PMid:25133510 PMCid:PMC4136732

14. Lang RM, Badano LP, Mor-Avi V, et al. Recommendations for cardiac chamber quantification by echocardiography in adults: an update from the American Society of Echocardiography and the European Association of Cardiovascular Imaging. J Am Soc Echocardiogr. 2015; 28(1):1-39. https://doi.org/10.1016/j.echo.2014.10.003

15. Vittinghoff $E$, McCulloch CE. Relaxing the rule of ten events per variable in logistic and Cox regression. Am J Epidemiol 2007 Mar 15;165(6):710-8. https://doi.org/10.1093/ aje/kwk052 PMid:17182981

16. Vizzardi E, Sciatti E, Bonadei I, Pezzali N, Lombardi C, Metra M. Red cell distribution width and chronic heart failure: prognostic role beyond echocardiographic parameters. Monaldi Archives for Chest Disease 2015;84:59:1-5. https://doi.org/10.4081/monaldi.2015.59

17. Kawasoe S, Kubozono T, Ojima S, Miyata M, Ohishi M. Combined Assessment of the Red Cell Distribution Width and B-type Natriuretic Peptide: A More Useful Prognostic Marker of Cardiovascular Mortality in Heart Failure Patients. Intern Med 2018 Jun 15;57(12):1681-8. https://doi.org/10.2169/internalmedicine.9846-17 PMid:29434163 PMCid:PMC6047991
18. Pilling LC, Atkins JL, Duff MO, Beaumont RN, Jones SE, Tyrrell J, et al. Red blood cell distribution width: Genetic evidence for aging pathways in 116,666 volunteers. PLoS One 2017;12(9):e0185083. https://doi.org/10.1371/ journal.pone.0185083 PMid:28957414 PMCid:PMC5619771

19. Lippi G, Pavesi F, Bardi M, Pipitone S. Lack of harmonization of red blood cell distribution width (RDW). Evaluation of four hematological analyzers. Clin Biochem 2014 Aug;47(12):1100-3. https://doi.org/10.1016/j.clinbiochem. 2014.06.003 PMid:24925288

20. Palmer L, Briggs C, McFadden S, Zini G, Burthem J, Rozenberg $\mathrm{G}$, et al. ICSH recommendations for the standardization of nomenclature and grading of peripheral blood cell morphological features. Int J Lab Hematol 2015 Jun;37(3):287-303. https://doi.org/10.1111/ijlh.12327 PMid:25728865

21. Morris T, Stables M, Hobbs A, de SP, Colville-Nash P, Warner $T$, et al. Effects of low-dose aspirin on acute inflammatory responses in humans. J Immunol 2009 Aug 1;183(3):208996. https://doi.org/10.4049/jimmunol.0900477 PMid: 19597002

22. Mavridis G, Souliou E, Diza E, Symeonidis G, Pastore F, Vassiliou AM, et al. Inflammatory cytokines in insulintreated patients with type 2 diabetes. Nutr Metab Cardiovasc Dis 2008 Sep;18(7):471-6. https://doi.org/ 10.1016/j.numecd.2007.02.013 PMid:17976964

23. Mirkov I, Popov AA, Demenesku J, Ninkov M, Mileusnic D, Kataranovski $D$, et al. Warfarin affects acute inflammatory response induced by subcutaneous polyvinyl sponge implantation in rats. Cutan Ocul Toxicol 2017 Sep;36(3):283-8. https://doi.org/10.1080/15569527.2016. 1275664 PMid:28067070

24. Hofbauer R, Frass M, Pasching E, Gmeiner B, Kaye AD, Kapiotis $S$. Furosemide and spironolactone reduce transmigration of leukocytes through endothelial cell monolayers. J Toxicol Environ Health A 2002 May 10;65(9):685-93. https://doi.org/10.1080/15287390252900 386 PMid:11996409

25. Wang S, Xiang YY, Ellis R, Wattie J, Feng M, Inman MD, et al. Effects of furosemide on allergic asthmatic responses in mice. Clin Exp Allergy 2011 Oct;41(10):1456-67. https://doi.org/10.1111/j.1365-2222.2011.03811.x PMid:21729180 